\title{
Crohn's Disease of the Jejunum in Children
}

\author{
A. R. CHRISPIN and E. TEMPANY \\ From The Hospital for Sick Children, Great Ormond Street, London W.C.1
}

Crohn's disease solely affecting the jejunum in the first instance is uncommon (Crohn, 1949; Van Patter, Bargen, Dockerty, Feldman, Mayo, and Waugh, 1954; Ginzberg, Marshak, and Eliasoph, 1960), and seems particularly uncommon in childhood. The case histories of four children with Crohn's disease of the jejunum are presented. The mode of presentation and the problems of diagnosis and management are discussed.

\section{Case Reports}

Case 1. When first seen in 1954 this 10-year-old boy's appetite had been poor for 3 years and in the previous 2 years he had lost $1.5 \mathrm{~kg}$. in weight. He had not grown in height. He had vomited intermittently for 16 months, but during this time there had been a complete remission for 5 months. The vomitus at times contained food eaten over 24 hours before, and it had been bile-stained. He described a central abdominal lump preceding a bout of vomiting and disappearing afterwards. Mild attacks of central abdominal colic had also occurred. He tended to be constipated during attacks of vomiting and only once had he passed a rather large offensive stool. Until this illness his progress from birth had been normal except for a mild flexural eczema.

Family history. The patient was an only child. Father had had a perforated duodenal ulcer 5 years previously.

Clinical examination. The boy was underweight $(24.5 \mathrm{~kg}$.). Other abnormal findings were confined to the alimentary system. His teeth were carious. He had peristaltic waves visible at times in the middle of the abdomen but no abdominal mass was palpable.

Investigations at first admission. Barium studies of the gastro-intestinal tract showed a grossly dilated proximal loop of jejunum which emptied slowly over many hours through a narrow segment (Fig. 1). The findings were those of Crohn's disease limited to the jejunum. ESR $12 \mathrm{~mm}$. $/ \mathrm{hr}$.; Hb $10.5 \mathrm{~g}$. $/ 100 \mathrm{ml}$., with $5 \cdot 3$ million $\mathrm{RBC} / \mathrm{c} . \mathrm{mm}$. Plasma proteins $5 \cdot 8 \mathrm{~g} . / 100 \mathrm{ml}$. No proteinuria present. No faecal occult blood. Faecal fat: $28 \%$ of dry weight.

Treatwent and progress. He was given a low-residue high-protein diet with potassium, calcium, and iron supplements and cortisone $75 \mathrm{mg}$./day. There was no clinical or radiological improvement within five weeks.

Received February 6, 1967.
Plasma proteins fell to $4 \cdot 1 \mathrm{~g} . / 100 \mathrm{ml}$. (albumin $1 \cdot 2$, globulin $2 \cdot 8$, with normal globulin pattern).

An entero-anastomosis bypassing the narrowed jejunum was carried out by Mr. David Waterston who found the jejunum proximal to the narrowed segment to be dilated and hypertrophied. The diseased segment was $50 \mathrm{~cm}$. long with a short 'skip' area towards its distal end. It was thickened, inflamed, and congested. The mesenteric glands were enlarged and subserosal lymphatics dilated. Appearances indicated Crohn's disease of the jejunum, the remainder of the gut being unaffected.

Following the operation he made excellent progress. His appetite rapidly improved and he gained $12 \mathrm{~cm}$. in

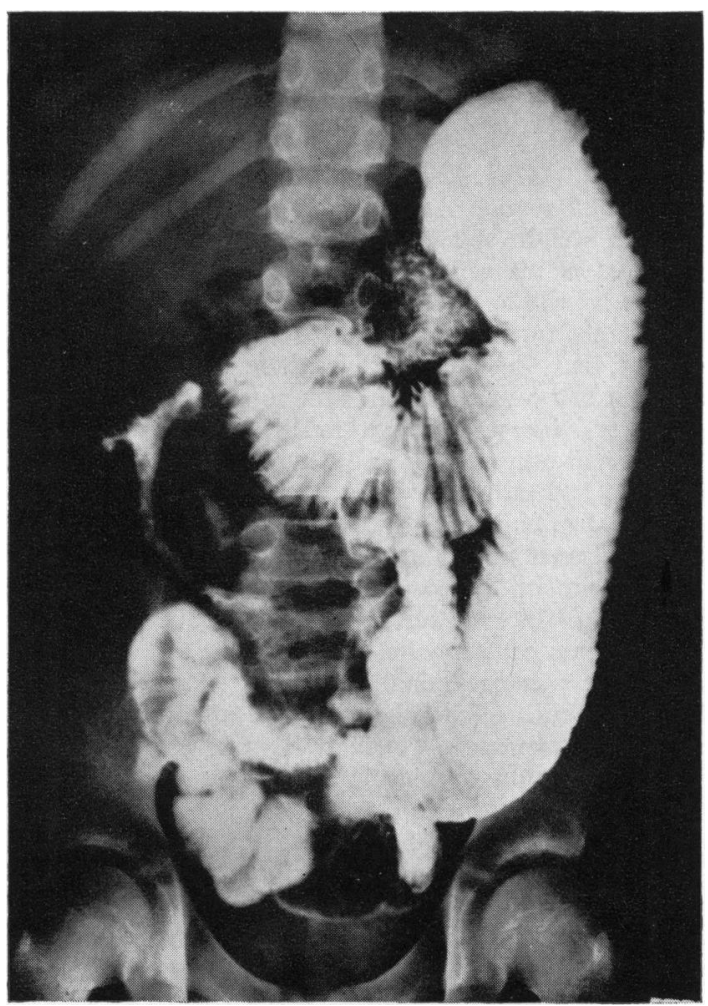

Fig. 1.-Case 1. A grossly dilated loop of jejunum proximal to the stricture. 
height and $16 \mathrm{~kg}$. in weight in the succeeding 18 months. The quality of his life was transformed and he was fit for the next six years. In 1960 he had abdominal pain for 3 months and was admitted to Saint Alfege's Hospital. Laparotomy was performed; active Crohn's disease was observed but no resection was carried out. Thereafter abdominal pain recurred from time to time.

When seen at King's College Hospital in 1962, aged 18, he had developed a general malaise and a low-grade fever. A diffuse tender mass could be felt in the umbilical area.

Investigations at second admission. $\mathrm{ESR} 33 \mathrm{~mm} . / \mathrm{hr}$.; Hb $10 \cdot 2$ g./100 ml., with macrocytosis present; 2 out of 3 faecal occult blood tests were positive. Barium meal and follow-through examination failed to demonstrate the site of abnormality. Treatment with ACTH was followed by cortisone. He was given a blood transfusion and also oral iron to correct the anaemia. After 2 months there had been no general improvement. Therefore a further laparotomy was performed. $\mathrm{Mr}$. Harold Edwards found a grossly thickened diseased loop of jejunum drawn back to the pancreas by oedematous mesentery containing large glands, some of which had broken down to form a small abscess cavity. No 'skip' area was observed. The diseased segment was removed and the patient made an excellent recovery. The resected jejunum was $50 \mathrm{~cm}$. long. It was grossly thickened and showed marked stenosis. Histological examination showed fibrosis and chronic inflammatory changes in all layers of its wall. In some areas noncaseating tubercle-like follicles were observed.

Case 2. This 12-year-old boy was healthy until the age of 7 years. At that time his parents said he did not gain weight as rapidly and his growth was slower than that of his contemporaries. He was admitted to hospital at the age of 9 years. He had then failed to gain weight for one year, his appetite was poor, and his parents had detected a low-grade evening pyrexia. Fainting had occurred from time to time.

Family history. Parents healthy; maternal grandmother had polyarthritis and 'thyroid trouble'; paternal aunt had had asthma.

Clinical examination. Apart from pallor and finger clubbing, no abnormality was found.

Investigations at first admission. ESR $31 \mathrm{~mm} . / \mathrm{hr}$.; Hb 10.5 g. $/ 100 \mathrm{ml}$.; serum iron $44 \mu \mathrm{g} . / 100 \mathrm{ml}$.; serum iron-binding capacity $264 \mu \mathrm{g} . / 100 \mathrm{ml}$. Faecal occult blood test was occasionally positive. Plasma proteins 5.6 g. $/ 100 \mathrm{ml}$.; electrophoresis showed some reduction in albumin fraction. Urinalysis was normal except that many amino acid levels were at the upper limit of normal. Liver function tests normal. Barium meal showed a normal oesophagus, stomach, and duodenum.

His anaemia was treated with iron and he was discharged from hospital. During the next six months his appetite and general condition improved but his anaemia persisted. Subsequently a raised ESR was repeatedly found, and on one occasion an eosinophilia of $9 \%$. No pathogens, cysts, or ova were ever discovered in his stools.

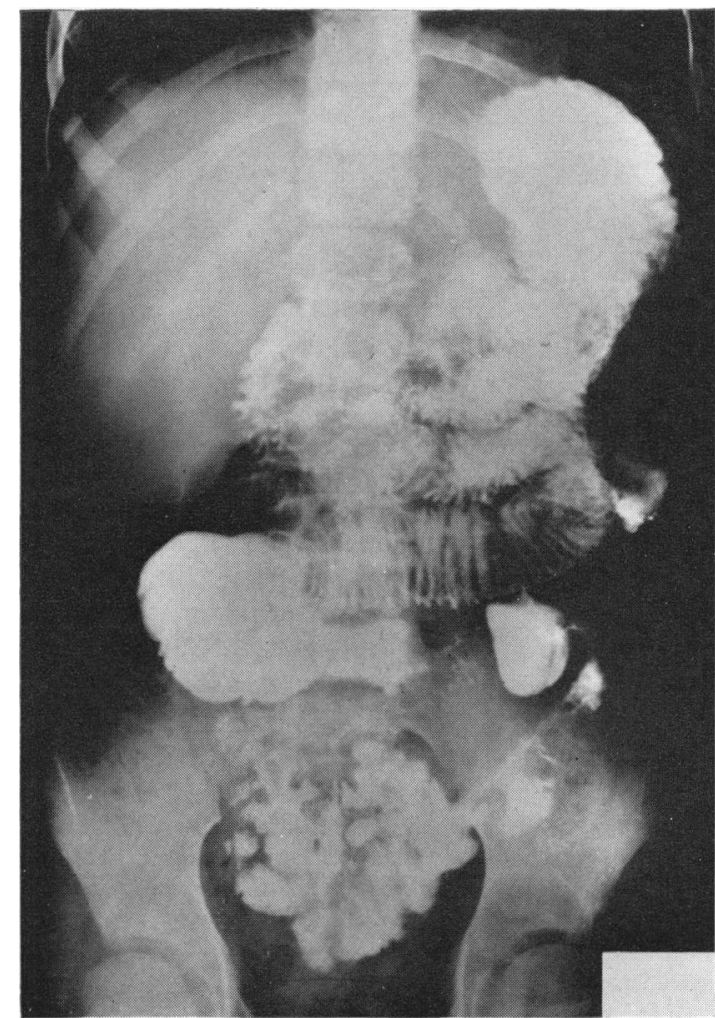

Fig. 2.-Case 2. Dilatation of the jejunum proximal to a stenosed segment within which the degree of stenosis is variable.

He was readmitted at the age of 11 years 10 months because his appetite was bad, he had vomited a little, and he complained of some abdominal discomfort. Physical examination revealed no new abnormality.

Investigations at second admission. ESR $15 \mathrm{~mm}$./hr.; $\mathrm{Hb} 11.4 \mathrm{~g} . / 100 \mathrm{ml}$. Stools, occult blood slightly positive. Plasma proteins $4.9 \mathrm{~g} . / 100 \mathrm{ml}$. total, electrophoresis showing a moderate reduction in albumin fraction. Liver function normal. No proteinuria. Barium meal showed a dilated segment of jejunum proximal to a stenosed segment (Fig. 2). The degree of stenosis was variable with small segments relatively less severely narrowed.

Laparotomy was performed by $\mathrm{Mr}$. Harold Nixon and the diseased segment was resected. Macroscopically the small intestine showed a segment $38 \mathrm{~cm}$. long where the whole of the wall was grossly thickened by fibrous tissue. The degree of stenosis was variable. Coarse nodularity of the mucosa was present and ulceration was particularly extensive proximally. Histological examination of sections taken from the region of maximal involvement showed the intestinal wall to be enormously thickened by oedema and diffuse fibrosis. There was extensive ulceration of the mucosa; the submucosa was thick and contained a heavy cellular infiltrate, mainly 
lymphocytic, but also including polymorphs and eosinophils; the muscle layers were almost completely obscured by diffuse fibrosis, and the serosa was thick and oedematous, with diffuse but especially perivascular infiltration. Numerous small lymphoid follicles were present in all layers of the wall. In the submucosa there were a few small abscesses and several small granulomata which consisted of epithelial and giant cells but none showed caseation or acid-fast bacilli. The findings were those of Crohn's disease confined to the jejunum.

In the two years following the operation the patient gained $19 \mathrm{~kg}$. in weight and grew $20 \mathrm{~cm}$. in height. His ESR became normal. Just over two years later he developed a 'perianal abscess' which was treated surgically. Tissue from its walls showed granulomata with giant cells. At this time he had no clinical, radiological, or sigmoidoscopic evidence of a gastro-intestinal recurrence.

Case 3. For $2 \frac{1}{2}$ years before admission this 11-yearold girl had night sweats and she lost weight over a period of a year. However, she continued attending school. For 18 months she had some ankle swelling and she had seemed pale. She had no diarrhoea, but her stools were rather pale and bulky, occurring once or twice each day. Her appetite was poor.

Family history. Parents healthy. Sister has ulcerative colitis.

Clinical examination. She was thin and pyrexial. She had clubbing of fingers and toes and oedema of the ankles. Stomatitis was present. No other abnormal findings presented on physical examination.

Investigations. ESR $12 \mathrm{~mm}$. $/ \mathrm{hr}$. $\mathrm{Hb} 6.8 \mathrm{~g} . / 100 \mathrm{ml}$. Occult blood was repeatedly detected in faeces. Plasma proteins $3.5 \mathrm{~g} . / 100 \mathrm{ml}$. total, electrophoresis showing marked reduction in albumin fraction and slight increase in $a_{1^{-}}$and $\gamma$-globulin fractions. No proteinuria was present and liver function was normal. $11.3 \%$ of the intravenous dose of ${ }^{51} \mathrm{Cr}$ was excreted in the stools in 5 days. Fat balance studies showed a $91 \%$ absorption over 5 days. Barium meal showed thick folds in the most proximal part of the jejunum, with a loss of the normal feathery pattern (Fig. 3). Beyond this the jejunum showed many strictures with dilatation of the bowel between the strictures. Radiographs of the skeleton showed a much reduced bone mineral content with partial collapse in the body of vertebra D7. No rachitic changes were observed and appearances seemed to favour osteoporosis.

A diagnosis of Crohn's disease of the jejunum was made and treatment with blood transfusion, steroids, and tetracycline was given. She showed a good symptomatic improvement but still had a slightly raised ESR and a mild intermittent pyrexia.

Case 4. When aged 11 years this boy had an anal fissure which later healed. Between the ages of 12 and 14 years he failed to increase his height $(146 \mathrm{~cm}$.) and his weight fell to $25 \mathrm{~kg}$. His appetite was very poor. He had attacks of bronchitis. He had an intermittent

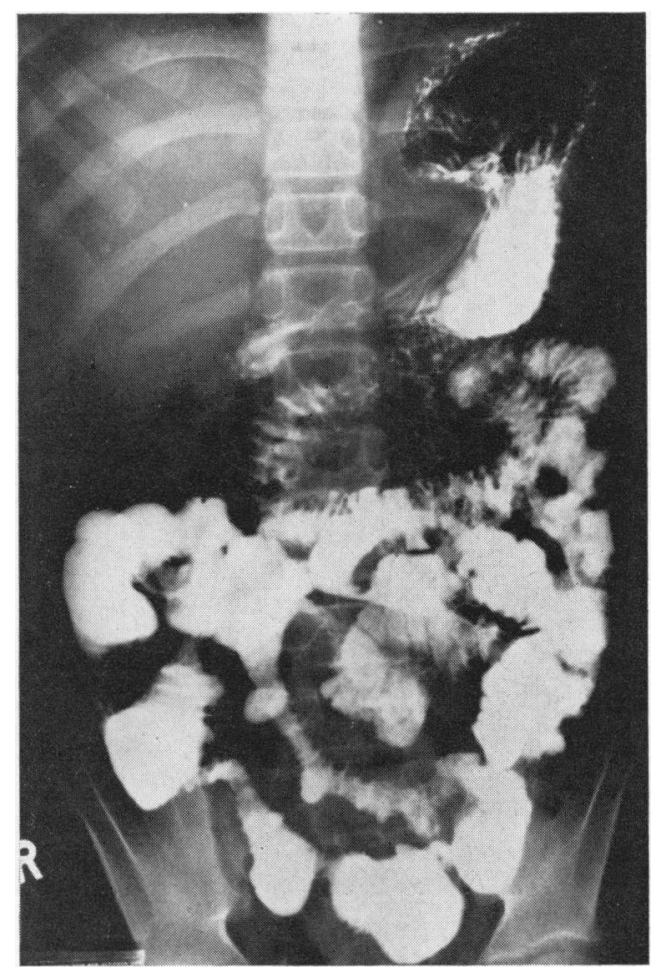

Fig. 3.-Case 3. Thick coarse folds in the most proximal part of the jejunum. Distally there is a long segment showing many stenoses.

fever and finger clubbing. No mass was palpable in the abdomen.

Investigations. $\mathrm{Hb} 7 \cdot 2 \mathrm{~g} . / 100 \mathrm{ml}$.; serum iron $62 \mu \mathrm{g}$./ $100 \mathrm{ml}$.; serum iron-binding capacity $172 \mu \mathrm{g} . / 100 \mathrm{ml}$.; occult blood detected in some stools; ESR $40 \mathrm{~mm}$./hr.; plasma proteins $5.8 \mathrm{~g} . / 100 \mathrm{ml}$. (albumin $2.4 \mathrm{~g} . / 100 \mathrm{ml}$.); tests of liver function normal and there was no proteinuria; $17 \%$ of the intravenous dose of ${ }^{51} \mathrm{Cr}$ was excreted in the stools in 5 days; fat balance studies showed $84 \%$ absorption of a $322 \mathrm{~g}$. fat intake. Radiological studies indicated Crohn's disease confined to the jejunum, of which about $80 \mathrm{~cm}$. were involved (Fig. 4). There was some narrowing but no stricture formation or obstruction in spite of the duration of symptoms.

Dietetic management with supplements but without steroid therapy has been associated, initially, with a good weight gain.

\section{Discussion}

Two patients became unwell at age 7 years, the third at $8 \frac{1}{2}$ years, and the fourth at 11 years. Early in the disease few gastro-intestinal symptoms were present: Ginzberg et al. (1960) have noted this in adults. No patient had diarrhoea. Vomiting was never marked though two patients had obstruction. 


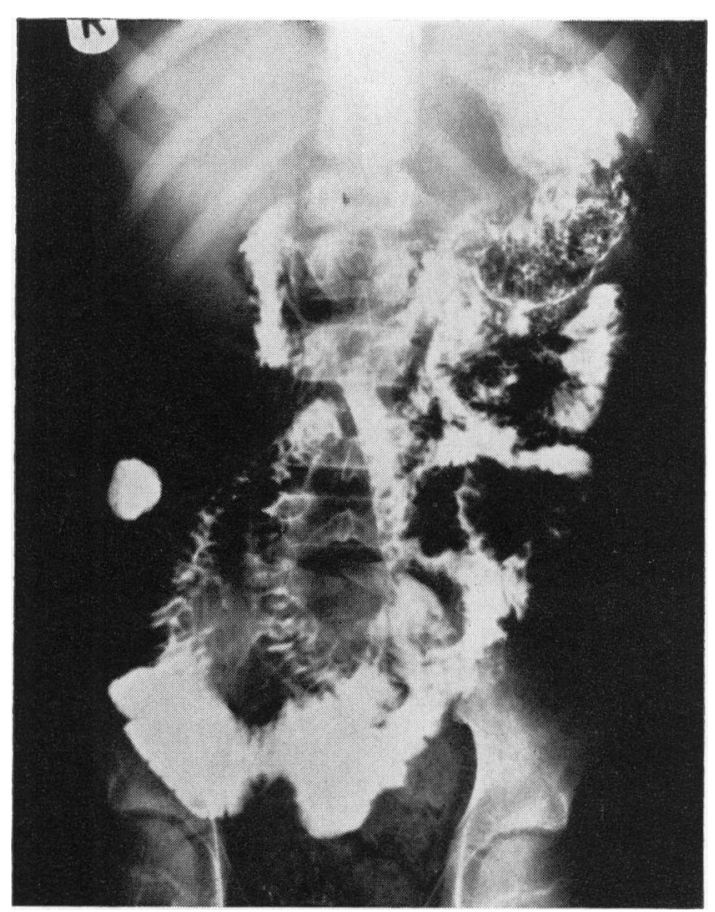

Fig. 4.-Case 4. Thick coarse folds throughout a narrowed jejunal segment. As in Fig. 3, the lumen of the gut has a spiky contour and one very deep ulcer is seen on the right side at the L.4-5 level. In all illustrations there is separation of the shadows of the diseased gut loops due to thickening of the bowel wall.

No abdominal mass was palpable in any patient but two experienced some abdominal pain. Three patients had fever, finger clubbing, and stools positive for occult blood. Features common to all four were anaemia and hypoproteinaemia. In two children (Cases 3 and 4) excessive gastro-intestinal protein loss was confirmed by isotope studies. In one child (Case 3) hypoproteinaemia was sufficiently severe to cause oedema. Thus, the dominant clinical features are the systemic manifestations of the disease.

Hypoproteinaemia and associated enteric protein loss has been observed in a number of childhood diseases. Among these are coeliac disease (Parkins, 1960), Hirschsprung's disease (Griffin, 1961), and the condition of hypoproteinaemia with a small intestinal abnormality characterized by the presence of dilated lacteals in the mucosa on jejunal biopsy. None of these seems likely to provide difficulty in differential diagnosis. Ulcerative colitis may be associated with hypoproteinaemia and protein loss into the lumen of the gut (Steinfeld, Davidson, and Gordon, 1957), but its clinical presentation is usually fairly distinctive and investigations are confirmatory.

Jarnum (1963) observed that hypoproteinaemia was a common feature of Crohn's disease, and considered it largely due to abnormal intestinal protein loss. In view of the ulceration of the mucosa, the inflammatory change involving all layers of the bowel wall, the large inflamed lymphatic glands, and the presumptive obstruction of lymphatic channels, this is understandable, especially in the acute exudative phase. What is surprising is the severity of plasma protein depression observed even when relatively short segments of bowel are seen to be involved (Cases 1 and 2). In addition to the mucosal lesion, other interrelated factors are probably important, namely (1) the dilated segment proximal to the lesion, and the dilatations of gut between strictures which are in essence 'blind loops'; (2) the poor appetite which results in a low calorie intake; and (3) because of the systemic manifestations of the lesion (e.g. pyrexia) even normal metabolic requirements for growth are not fulfilled.

The silent way in which jejunal strictures due to Crohn's disease may develop has been emphasized by Shoesmith, Tate, and Wright (1964). Case 1 initially showed this feature of the condition. In Case 2 obstruction was preceded by prolonged ill health with systemic manifestations. The disease in Case 3 at one time followed a much more acute course with a marked fever, raised ESR, and a severe hypoproteinaemia. Anorexia and emaciation were outstanding features of Case 4. The skeletal decalcification observed in the radiographs in Case 3 is presumably related to metabolic disturbances associated with the protein-losing enteropathy, steatorrhoea, and general ill health.

The family histories of asthma, polyarthritis, and thyroid disease in one patient (Case 2) and of ulcerative colitis in another (Case 3) are noteworthy.

Management of patients with Crohn's disease; a condition noted for its chronicity and its exacerbations and remissions, presents formidable problems. In the jejunal form, where the element of obstruction due to stricture formation has become marked, operative intervention is indicated. Initially the post-operative course can be extremely satisfactory (Cases 1 and 2). That surgical treatment for obstruction can give a long-term satisfactory result is emphasized by the course of the disease in Case 1 (first reported by Webb, 1956); a period of 6 years of good health followed the operation. At the age of 18 years ( 8 years later) he required a surgical resection. In Case 3 conservative management seems preferable at the present, for though 
stenoses are developing, there is no evidence of obstruction and there is a considerable length of gut involved. Clinically it appears that a subacute phase has been entered and it may be that steroids and antibiotics are proving helpful. However, conservative management without steroid therapy has been associated with a good initial response in Case 4.

Fistula formation in Crohn's disease of the ileum and colon is a well-recognized phenomenon. In the jejunal form of the disease it appears to be singularly uncommon (Ginzberg et al., 1960) and has not occurred in any of the four patients. Anal fissure was an early feature in Case 4. Following jejunal resection Case 2 developed a 'perianal abscess', but there was no other clinical or radiological evidence of recurrence. In Crohn's disease patients may develop such perianal lesions, with evidence of local granulomatous changes (Van Patter et al., 1954; Lockhart-Mummery and Morson, 1964).

\section{Summary}

In Crohn's disease of the jejunum in four children the dominant clinical features have been the systemic manifestations, namely, failure to gain in height and weight, finger clubbing, mild fever, anaemia, and high ESR. There has been a dearth of such gastro-intestinal symptoms as diarrhoea, vomiting, pain, and abdominal masses. Low plasma proteins have been found: excessive enteric protein loss was demonstrated in two patients. Problems of management are discussed.

We are indebted to Sir Wilfred Sheldon, Professor N. Butler, Professor O. H. Wolff, Mr. D. J. Waterston, Mr. H. Nixon, and Mr. G. Fraser of The Hospital for Sick Children, and Mr. H. Edwards of King's College Hospital, whose patients we report.

\section{REFERENCES}

Crohn, B. B. (1949). Regional Ileitis. Staples Press, London. Ginzberg, L., Marshak, R. H., and Eliasoph, J. (1960). Regional jejunitis. Surg. Gynec. Obstet., 111, 626.

Griffin, J. W. (1961). Congenital megacolon (Hirschsprung's disease) associated with hypoproteinemia and edema. F. Pediat., $59,394$.

Jarnum, S. (1963). Protein-losing Gastroenteropathy, p. 173. Blackwell, Oxford.

Lockhart-Mummery, H. E., and Morson, B. C. (1964). Crohn's disease of the large intestine. Gut, 5, 493.

Parkins, R. A. (1960). Protein-losing enteropathy in the sprue syndrome. Lancet, 2, 1366.

Shoesmith, J. H., Tate, G. T., and Wright, C. J. E. (1964). Multiple strictures of the jejunum. Gut, 5, 132.

Steinfeld, J. L., Davidson, J. D., and Gordon, R. S. (1957). A mechanism for hypoalbumenemia in patients with ulcerative colitis and regional enteritis. f. clin. Invest., 36, 931.

Van Patter, W. N., Bargen, J. A., Dockerty, M. B., Feldman, W. N., Mayo, C. W., and Waugh, J. M. (1954). Regional enteritis, 1954. Gastroenterology, 26, 347.

Webb, B. (1956). Chronic regional enteritis in childhood. Gt Ormond Str. f., 11, 76. 